OPEN ACCESS

Edited by:

Roderick William Boswell, Australian National University, Australia

Reviewed by:

Mitchell L. R. Walker,

Georgia Institute of Technology,

United States

Wonho Choe,

Korea Advanced Institute of Science and Technology, South Korea

Amelia Greig,

The University of Texas at El Paso,

United States

*Correspondence:

Kazunori Takahashi

kazunori@ecei.tohoku.ac.jp

Specialty section:

This article was submitted to

Plasma Physics,

a section of the journa

Frontiers in Physics

Received: 08 December 2020 Accepted: 08 March 2021

Published: 31 March 2021

Citation:

Takahashi $K$, Imai $R$ and Hanaoka $K$ (2021) Automatically Controlled

Frequency-Tunable if Plasma

Thruster: Ion Beam and Thrust

Measurements.

Front. Phys. 9:639010.

doi: 10.3389/fphy.2021.639010

\section{Automatically Controlled Frequency-Tunable rf Plasma Thruster: lon Beam and Thrust Measurements}

\author{
Kazunori Takahashi ${ }^{*}$, Ryoji Imai and Kengo Hanaoka \\ Department of Electrical Engineering, Tohoku University, Sendai, Japan
}

A fast and automatically controlled frequency-tunable radiofrequency ( $\mathrm{rf}$ ) system is installed in an if plasma thruster consisting of a stepped-diameter insulator source tube wound by a single-turn loop antenna and a solenoid providing a magnetic nozzle, and immersed in vacuum. The frequency and the output power are controlled so as to minimize the reflection coefficient and to maintain the net power corresponding to the forward minus reflected powers at a constant level. The reproducibility of the impedance matching and the stability of the net if power are assessed, showing the fast impedance matching within about $10 \mathrm{msec}$ and the long and stable delivery of the if power to the thruster. When increasing the if power up to $500 \mathrm{~W}$, discontinuous changes in the source plasma density, the imparted thrust, and the signal intensity of the ion beam downstream of the thruster are observed, indicating effects of the discharge mode on the thruster performance and the ion energy distribution.

Keywords: rf plasma thruster, impedance matching, rf generator, thrust, ion beam

\section{INTRODUCTION}

Spontaneous accelerations of charged particles can be frequently observed in space, astrophysical, and laboratory plasmas $[1,2]$. Especially, unmagnetized ions having a mass much heavier than the electrons are significantly affected by electric fields rather than magnetic fields; hence the potential structure plays an important role in the ion acceleration processes in weakly magnetized plasmas [3-5]. When a plasma density decays due to a volume expansion, an axial electric field accelerating the ions and confining the electrons develops in the plasmas. Charles and Boswell have discovered a formation of a current-free electric double layer, which has a potential drop over a narrow region of about a few tens of Debye length, in the magnetically expanding radiofrequency (rf) plasmas [6]. A number of subsequent experiments have also shown the similar structure or a broader (but still narrower than the scale of the magnetic field gradient) potential drop over about $10 \mathrm{~cm}$ in the expanding magnetic fields [7-16]. Measurements of ion energy distributions by using a retarding field energy analyzer and a laser-induced fluorescence method have shown a generation of a supersonic ion beam at the low-potential side, where the number of the beam ions decays along the axis due to a charge exchange process [7]. The magnetic field configuration and strength are key parameters in the spontaneous ion acceleration phenomenon as demonstrated before $[17,18]$, where the ion beam is generated when the Larmor radius of the ions becomes smaller than the source radius [19]. 
Measurement of an electron energy probability function (eepf) in the magnetically expanding rf plasma has identified the presence of the two species of electrons: trapped and free electrons, where the high energy (but low temperature population) electrons overcome the potential drop and neutralize the accelerated ion beam [20]. Since the energy source of the potential drop is considered to be the electron energy as discussed in [21], the electron energy distribution significantly affects the ion acceleration energy. Actually, the increases in both the ion beam energy and the electron temperature with a decrease in the operating gas pressure have been detected so far [16, 22, 23].

Thrusts imparted by magnetic nozzle rf plasma thrusters have been assessed for the last decade by using thrust balances [2429], where the thrust is the reaction force of the momentum exhausted from the system per unit time. The above-mentioned electrostatic ion acceleration does not increase the thrust due to the absences of both any external energy source and the vector conversion of the momentum [30]. However, the generation of the collimated ion beam would be beneficial for the thruster since the accelerated ions can be detached from the magnetic field lines [31-35], where the electron detachment from the magnetic nozzle is still an open question [36-41]. The direct measurement of the force exerted to the magnetic field has demonstrated a thrust enhancement by the magnetic nozzle, where a Lorentz force arising from an azimuthal electron diamagnetic current and a radial magnetic field is exerted to the magnetic field, being equivalent to an electron pressure force to the expanding magnetic field [30, 42-44]. Various configurations of the thruster have been tested so far and the thruster efficiency has been gradually increased and approaches twenty percent in recent years [45]. Furthermore, a new application of the magnetic nozzle rf plasma thruster to contactless space debris removal has been proposed and the proof of the principle has been demonstrated in a laboratory experiment [46].

To mount the thruster on a spacecraft, development of peripheral components being compact, light, and robust, is also important issue. In early stage of fundamental studies, permanent magnet configurations, which lead eliminations of heavy solenoids and dc power supplies, have been designed to form the magnetic nozzles. Chen has demonstrated the efficient plasma production with annular permanent magnets [47]. One of authors and Virko et al. [10] have demonstrated the spontaneous ion acceleration in the expanding magnetic fields formed by the permanent magnets $[9,10]$. The $\mathrm{rf}$ system including a generator and a matching box often dominates the weight and volume of the thruster, in addition to the solenoids and the dc power supplies. Since the load impedance is significantly affected by plasma parameters (e.g., the plasma density and the electron temperature), the impedance tuning is an important element of the rf plasma thruster operation, especially with undefined composition of the propellant for an air-breathing electric propulsion and the use of propellants created from in situ resource utilization [48, 49]. The load impedance is typically adjusted by changing the variable capacitors in the matching circuit. This type of the matching circuit requires a mechanical motion control preventing the matching circuit from being compact. Furthermore, the time lag of the communication between the spacecraft and the ground control station would be a serious problem for the impedance matching; it would be desirable to include the automatic controller for the impedance tuning. To overcome the issue on the matching box, several types of the rf generators have adjusted the frequency to match the load impedance to the output impedance of the generator [5053], where fixed capacitors are used in the matching circuit. A recently developed fast and automatically controlled rf system has demonstrated the fast impedance matching for the rf plasma source [54], where the source tube is attached to a vacuum flange of a chamber and the rf antenna wound around the source tube is exposed to the atmosphere. On the other hand, the whole structure of the plasma source including the antenna has to be immersed in vacuum for the thruster assessment configuration.

Here the fast and automatically controlled rf system operational in the frequency range of $37-43 \mathrm{MHz}$ and with the maximum power of about $500 \mathrm{~W}$ is installed in the helicon plasma thruster immersed in vacuum, where the thruster is attached to a pendulum thrust balance. The impedance tuning can be typically accomplished within several msec and the net power (corresponding to the forward minus reflected powers) is maintained at a constant level during the discharge, providing the stable steady-state operation of the thruster. The imparted thrust and the ion energy distribution function are measured by using a thrust balance and a retarding field energy analyzer (RFEA), respectively, showing the thrust of a few $\mathrm{mN}$ for $500 \mathrm{~W}$ rf power and the spontaneous generation of the supersonic ion beam. Discontinuous increases in the thrust, the source plasma density, and the ion beam component, are clearly observed when increasing the rf power. The ion beam component enhanced simultaneously with the discharge mode transition implies that the presence of the high-density plasma at the high-potential side is useful to the increase in the ion beam current. The energy of the supersonic ion beam and the electron temperature increase with a decrease in the gas flow rate. The results are consistent with the previous experiments using $13.56 \mathrm{MHz}$ rf generators [2, 45].

\section{EXPERIMENTAL SETUP}

Figure 1A shows the schematic diagram of the experimental setup, together with the calculated magnetic field lines. A helicon thruster consists of a stepped-diameter ( $65-95 \mathrm{~mm}$ inner diameter and $70-100 \mathrm{~mm}$ outer diameter) pyrex glass source tube wound by a single-turn water-cooled rf loop antenna and a solenoid providing a static magnetic field expanding downstream of the source, i.e., the magnetic nozzle. The detailed structure of the thruster design can be found in Ref. [55] and the rf antenna is covered with insulators and further covered with a grounded metallic structure to suppress parasitic discharges outside the source tube [56]. The thruster is attached to a pendulum thrust balance installed inside a 1-m-diameter and 2-m-long cylindrical vacuum chamber, which is evacuated by three turbomolecular pumping [labeled as "TMP" in Figure 1A] systems to a base pressure lower than $10^{-4} \mathrm{~Pa}$. It is noted that the rf loop antenna is mechanically isolated from the source tube to ensure the pendulum motion of the thrust balance. The upstream side of 
the source is terminated by an insulator plate having a small gas injection port. Argon gas is continuously introduced from the gas injection port into the source tube via a mass flow controller located outside the chamber. For typical gas flow rate of $C_{\mathrm{Ar}}=70 \pm 1 \mathrm{sccm}$, the argon gas pressure measured at the chamber side wall is about $25 \pm 1 \mathrm{mPa}$. It should be mentioned that the thrust measurement for different pumping speeds, i.e., different gas pressures for the constant gas flow rate, has been performed previously, showing the unchanged thrust, where the measurement has been performed at 25 and $75 \mathrm{mPa}$ [57]. This implies that the thruster performance is not affected by the gas ingestion. The performance assessment at the lower gas pressure cannot be performed due to the limit of the vacuum facility. A dc current $I_{\mathrm{B}}$ is supplied to the solenoid to form the magnetic nozzle, where the calculated magnetic field strength on the $z$ axis is plotted in Figure 1B, showing that the magnetic field has a throat of about $650 \mathrm{G}$ at the larger-diameter region of the source tube $(z \sim-3.5 \mathrm{~cm})$. The $\mathrm{rf}$ antenna is powered from the rf generator (briefly described later) via an impedance matching circuit, resulting in a plasma production in the source tube, where the capacitances in the matching circuit are unchanged to demonstrate the automatic and fast control of the frequency tuning.

The rf generator is very similar to that used in the previous experiment [53], while the maximum output power can be increased up to about $500 \mathrm{~W}$ in the present setup. Briefly, it consists of a voltage-controlled oscillator (VCO), a voltagevariable attenuator (VVA), a main amplifier, a bi-directional coupler, and power detectors, as shown in Figure 2. A board controller (National Instruments, sbRIO-9637) is mounted on the system, which consists of a field-programmable gate array (FPGA) and analog-digital/digital-analog convertors. The board has digital-input (DI), digital-output (DO), analog-input (AI), and analog-output (AO) channels. The frequency and the power of the rf signal inputted to the main amplifier can be controlled by the AO signals to the VCO and the VVA, respectively. The amplified $\mathrm{rf}$ power is transferred to a load (including the capacitors and the plasma source) via the bi-directional coupler. The rf signals corresponding to the forward and reflected powers are converted into dc voltages by using coaxial schottky barrier diode detectors and the low pass filters (LPF), which are measured by the AI channels. A gate signal is inputted into the DI channels; the same signal outputted from the DO channel is inputted into the main amplifier to turn on the rf power. During the detection of a high logic level by the DI channel, the frequency and the power are controlled by the board so as to minimize the reflection coefficient and to maintain the net rf power at a constant level, where the reflection coefficient and the net power are calculated on the board from the measured forward $\left(P_{\mathrm{f}}\right)$ and reflected $\left(P_{\mathrm{r}}\right)$ powers as

$$
\begin{gathered}
\Gamma_{r}=\sqrt{\frac{P_{r}}{P_{f}}}, \\
P_{n e t}=P_{f}-P_{r},
\end{gathered}
$$

respectively. It should be noted that the power delivered to the load is not the forward power $P_{\mathrm{f}}$ but the net power $P_{\text {net }}$. The detected signals of the forward and reflected powers are calibrated by using an $\mathrm{rf}$ wattmeter with an accuracy of $5 \%$, resulting in errors of about $7.5 \%$ in $G_{\mathrm{r}}$ (for typical powers of $P_{\mathrm{f}}=500 \mathrm{~W}$ and $P_{\mathrm{r}}=20 \mathrm{~W}$ ) and about $5 \%$ in $P_{\text {net }}$. Typical dc-rf conversion efficiency in the main amplifier is about $74 \%$. To assess the overall efficiency of the source, estimation of the $\mathrm{rf}$ power delivered to the plasma, i.e., the rf power transfer efficiency to the plasma, is required. This has not been performed yet and remains a further experimental issue.

As shown in Figure 1A, the whole structure of the thruster is attached to a plate suspended by flexible thin metallic plates from a top plate of the thrust balance, where the length of the arms is about $24 \mathrm{~cm}$. The displacement induced by the plasma production is measured by a commercial laser displacement sensor with a resolution of $0.1 \mathrm{~mm}$. The absolute value of the thrust can be obtained by multiplying a calibration coefficient to the measured displacement, where the calibration coefficient is obtained by measuring the displacement vs. known force before pumping down the chamber and is confirmed to be unchanged after venting the chamber. The validity of the thrust measurement technique has been shown in the previous experiment with the comparison between the thrust balance and the target techniques [58].

The plasma density, the electron temperature, and the ion energy distribution function (IEDF) are measured by a radially facing 3-mm-diameter planar Langmuir probe mounted on a movable motor stage and an RFEA located at $z=25 \mathrm{~cm}$. The plasma density $n_{\mathrm{p}}$ can be obtained from an ion saturation current $I_{\text {is }}$ as

$$
I_{i s}=0.61 e n_{p} u_{B} S,
$$

where $e, u_{\mathrm{B}}$, and $S$ are the elementary charge, the Bohm velocity, and the surface area of the probe tip, respectively, and a measured electron temperature is used for the calculation of the Bohm velocity, e.g., $T_{\mathrm{e}} \sim 4.5 \pm 0.5 \mathrm{eV}$ for the gas flow rate of $70 \mathrm{sccm}$. As the detector faces in the radial direction, the estimated density corresponds to that of the thermal ions. The RFEA consists of a collector electrode and two meshes: the first mesh contacting the plasma is electrically floating and the second one is used as a repeller for the electrons. The IEDF is known to be proportional to the first derivative of the collector voltage $\left(V_{\mathrm{c}}\right)$-current $\left(I_{\mathrm{c}}\right)$ characteristic, which is obtained by a pulsed Langmuir probe technique [59].

\section{RESULTS}

Figure 3 shows the typical temporal evolutions of (A) the gate signal and the $\mathrm{rf}$ frequency $(f),(\mathbf{B})$ the forward $\left(P_{\mathrm{f}}\right)$ and reflected $\left(P_{\mathrm{r}}\right)$ powers, and $(\mathbf{C})$ the net power $\left(P_{\text {net }}\right)$ and the square of the reflection coefficient $\left(\Gamma_{\mathrm{r}}^{2}\right)$, where the initial value of the frequency, the pulse width of the rf power, and 


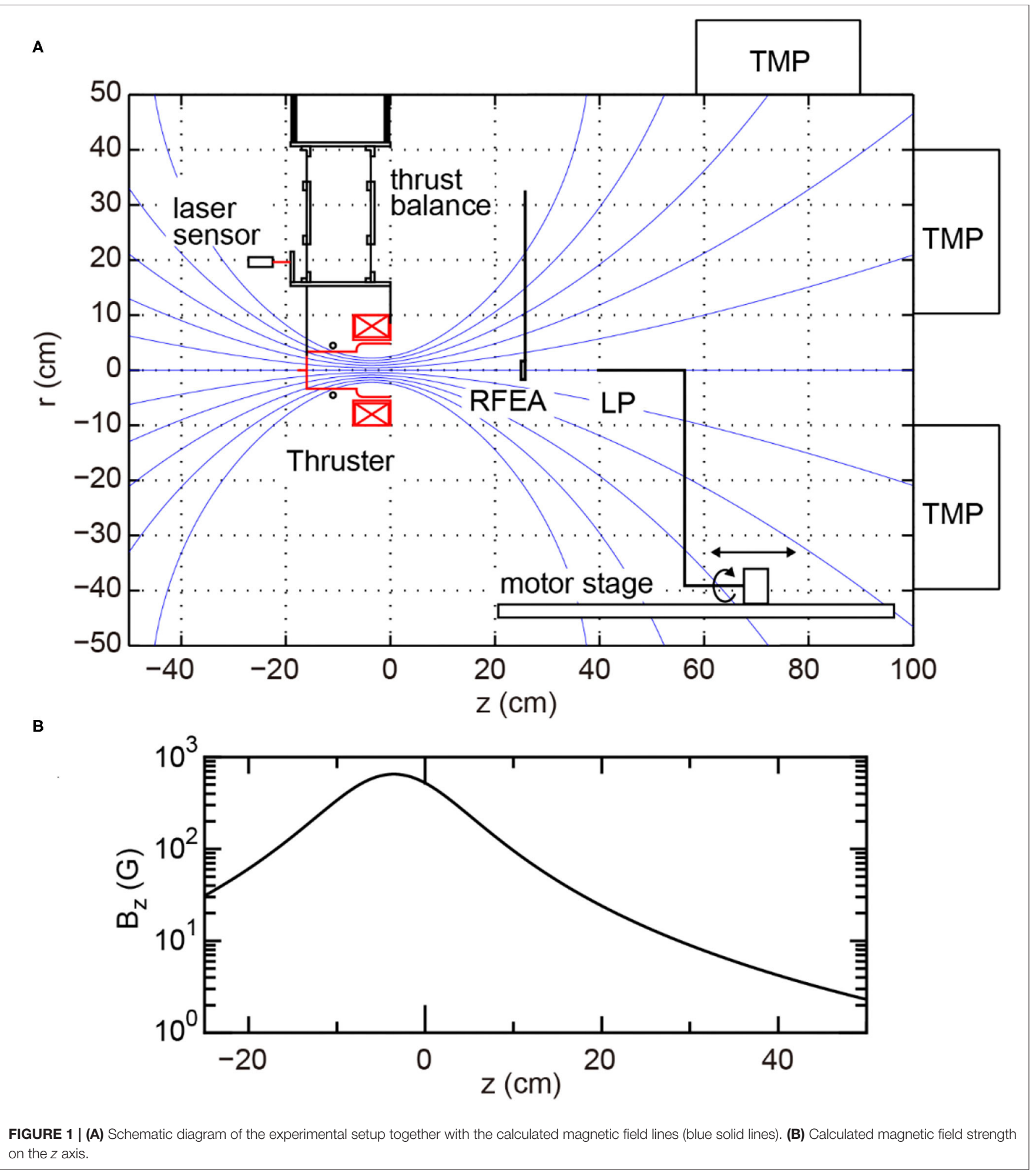

the target value of the net power are set at $\sim 39.1 \mathrm{MHz}$, $100 \mathrm{msec}$, and $500 \mathrm{~W}$, respectively. It is found that the $\mathrm{rf}$ frequency automatically changes from $\sim 39.1$ to $\sim 38.7 \mathrm{MHz}$ within the initial $7 \mathrm{msec}$; the value of $\Gamma_{\mathrm{r}}^{2}$ is significantly reduced from unity to 0.03 , corresponding to the power reflection of about $3 \%$, at $t \sim 7 \mathrm{msec}$. The net power $P_{\text {net }}$ is also found to approach the target value of $500 \mathrm{~W}$ during the pulse.

By taking data of 1,000 shots, the statistical analyses for the tuning time $\left(t_{\text {tune }}\right)$, the $\mathrm{rf}$ powers $\left(P_{\mathrm{f}}, P_{\mathrm{r}}, P_{\text {net }}\right)$, and the square of the reflection coefficient $\left(\Gamma_{\mathrm{r}}^{2}\right)$ are performed, where $t_{\text {tune }}$ is defined as the time spent for reducing the value of $\Gamma_{\mathrm{r}}^{2}$ to 


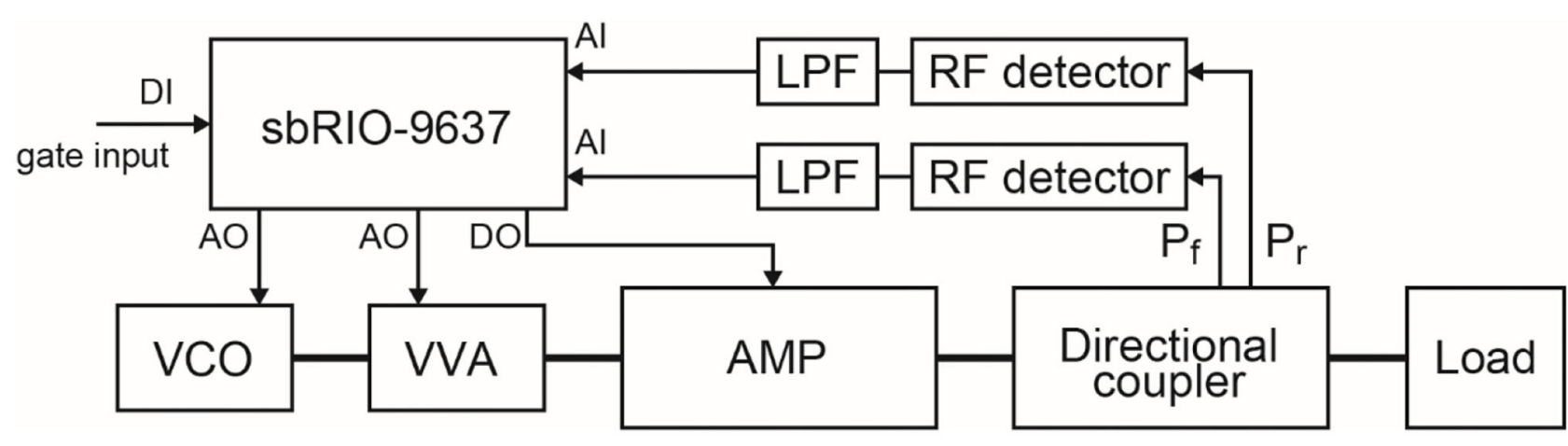

FIGURE 2 | Schematic circuit diagram of the rf system.

0.1. A probability density function (PDF) of $t_{\text {tune }}$ presented in Figure 4A shows the typical tuning time of about $7.5 \pm 0.5 \mathrm{msec}$ and the reproducibility can be confirmed from this PDF even in the thruster immersed in vacuum, as well as the previous experiment using the rf antenna exposed to atmosphere [60]. The PDFs of the rf powers and $\Gamma_{\mathrm{r}}^{2}$ presented in Figures $4 \mathrm{~B}, \mathrm{C}$, respectively, are calculated from the data for $t>50 \mathrm{msec}$ to discuss the power controllability in the steady state, implying the sharp peaks in the PDFs of the rf powers as seen in Figure 4B. The PDF of $\Gamma_{\mathrm{r}}^{2}$ in Figure 4C shows the reproduced impedance matching giving the power reflection of about $3 \%$. Therefore, the fast and automatically controlled rf system can be utilized in the thruster development, where the plasma source structure including the rf antenna is immersed in vacuum.

Steady state operation of the thruster is also an important issue. Figure 5 shows the measured $P_{\text {net }}$ and $f$ for the long pulse of $180 \mathrm{sec}$, where the target value of $P_{\text {net }}$ is set at $450 \mathrm{~W}$. It is found that the frequency is immediately changed from the initial 39.1 to $\sim 38.65 \mathrm{MHz}$ and slightly changed during the pulse. The slight change in the frequency seems to be due to the change in the wall temperature of the source tube, where the temperature of the water-cooled antenna is expected to be unchanged. It can be seen that $P_{\text {net }}$ is maintained at $450 \mathrm{~W}$ during the discharge pulse of $180 \mathrm{~s}$, indicating the stable operation of the rf system.

Measurement of the thrust as a function of $P_{\text {net }}$ is performed for the gas flow rate of $70 \mathrm{sccm}$ and the result is plotted by filled squares in Figure 6. The thrust is found to increase with an increase in the rf power and a slight discontinuous change can be seen at $P_{\text {net }} \sim 350 \mathrm{~W}$. Open circles in Figure 6 show the plasma density $n_{\mathrm{p}}$ measured by the Langmuir probe located at $z=-10 \mathrm{~cm}$ and the discontinuous jump of the density can be observed at the similar power of $P_{\text {net }} \sim 350 \mathrm{~W}$, which is considered to be due to the discharge mode transition from capacitively- to inductively-coupled discharges. The maximum thrust obtained in the present experiment is about $3.5 \mathrm{mN}$ for the rf power of $500 \mathrm{~W}$, which seems to be similar to that obtained with $13.56 \mathrm{MHz}$ rf generator [55].

Figure 7a shows the typical IEDF (blue solid line) taken at $z=$ $25 \mathrm{~cm}$ for the gas flow rate of $C_{\mathrm{Ar}}=70 \mathrm{sccm}$ and the net power of $P_{\text {net }}=500 \mathrm{~W}$, clearly showing the two peaks corresponding to the low-energy thermal ions at $\sim 38 \mathrm{~V}$ (plasma potential) and the high-energy beam ions at $\sim 51 \mathrm{~V}$ (beam potential). The measured data can be well-fitted by a superimposition of two Gaussians (dashed lines) as drawn by a red solid line. Figure $\mathbf{7 b}$ shows the normalized IEDFs as a function of $P_{\text {net }}$, where the fitting curves are used to draw the contour plot. At the net rf power of $P_{\text {net }}$ $\sim 350 \mathrm{~W}$, the peak of the ion beam is found to be enhanced simultaneously with the discharge mode transition observed in Figure 6. Therefore, it is demonstrated that the discharge mode inside the source significantly affects the ion energy distribution function downstream of the source tube; the presence of the highdensity plasma in the source tube can yield the increase in the ions accelerated from the high- to low-potential sides.

Figure 8A shows the axial profile of the plasma density $n_{\mathrm{p}}$ for the same conditions as Figure $7 \mathbf{a}$ and the axial decay of the density is enhanced near the thruster exit $(z=0-10 \mathrm{~cm})$. When assuming a uniform electron temperature, the voltage $V$ from the reference position (density of $n_{\mathrm{p} 0}$ ) can be given by the Boltzmann relation as

$$
V=T_{e} \ln \left(\frac{n_{p}}{n_{p 0}}\right)
$$

and the calculated $V$ from the data in Figure $\mathbf{8 A}$ is plotted in Figure 8B. It is noted that the difference between the plasma and beam potentials in the IEDF taken at $z=25 \mathrm{~cm}$ is about $12.5 \mathrm{~V}$ as seen in Figure 7a. A red dashed line in Figure $\mathbf{8 B}$ indicates the axial position giving the $12.5-\mathrm{V}$-higher potential than that at $z=$ $25 \mathrm{~cm}$. This result implies that the accelerated ion beam comes from the high potential side near the thruster exit. The velocity of the $12.5 \mathrm{eV}$ ions is about $7.7 \mathrm{~km} / \mathrm{sec}$, while the ion sound speed corresponding to the Bohm velocity for $T_{\mathrm{e}}=4.5 \mathrm{eV}$ is about $3.3 \mathrm{~km} / \mathrm{sec}$. Therefore, the ion Mach number can be estimated as $\sim 2.3$ and the detected ion beam is found to be supersonic. It should be mentioned that the IEDFs in the present experiment (Figure 7) seem to be broadened, compared with that observed in the previous experiment showing the formation of the currentfree double layer, which has a nearly discontinuous potential drop [61]. Possible reasons of the broadened IEDF are a poor energy 
A

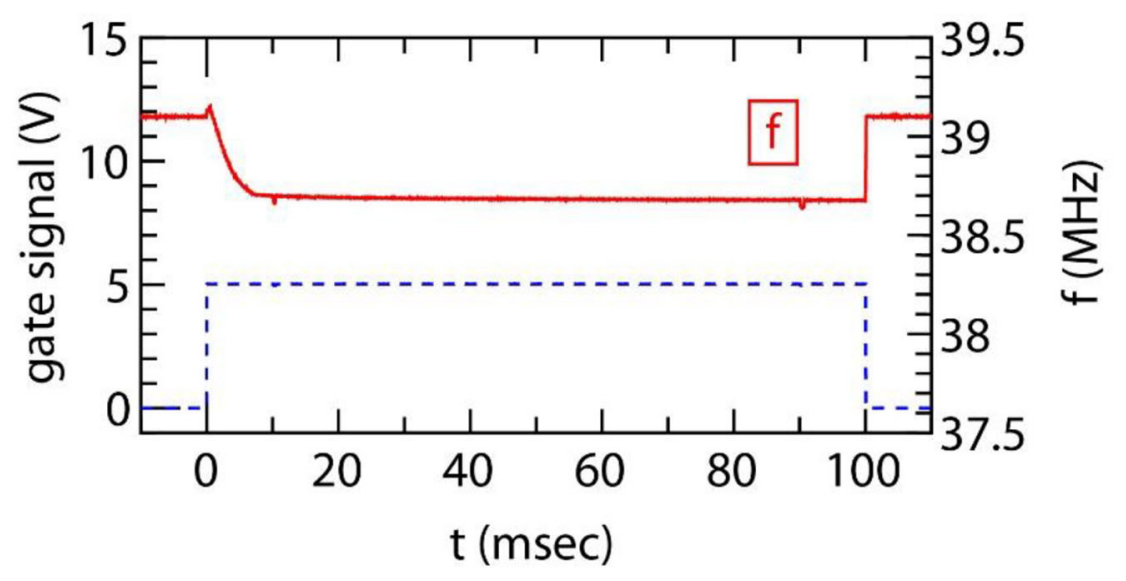

B
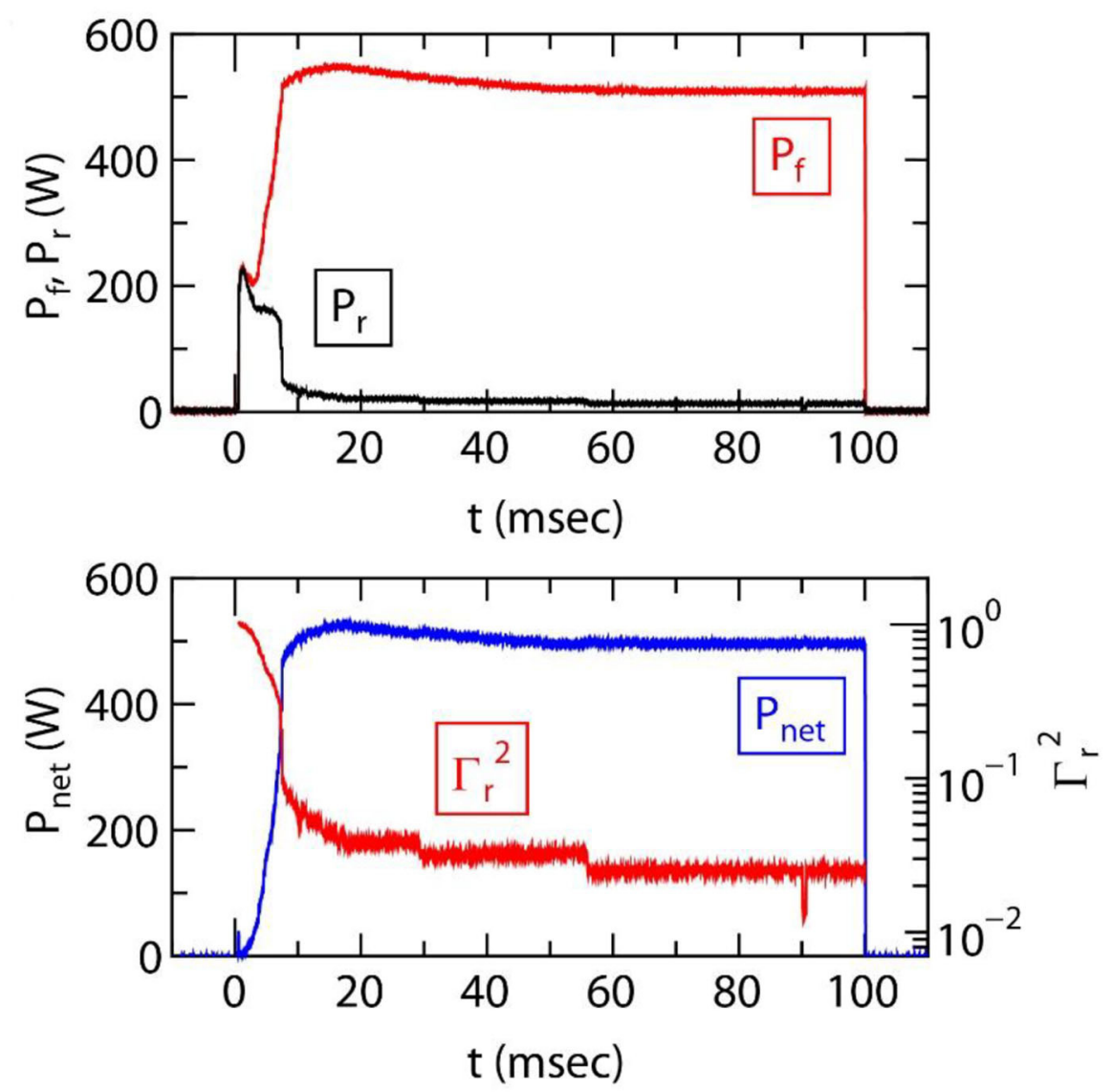

FIGURE 3 | Temporal evolutions of (A) the rf gate signal (a dashed line), the frequency $f$ of the rf power (a red solid line), (B) the forward power $P_{f}(\mathrm{a}$ red solid line), the reflected power $P_{\mathrm{r}}$ (a black solid line), (C) the net if power $P_{\text {net }}$ (a blue solid line), and the square of the reflection coefficient $\Gamma_{\mathrm{r}}^{2}$ (a red sold line), where the pulse width of the rf power, the initial value of the frequency, and the target value of the net power, are set at $100 \mathrm{msec}, 39.1 \mathrm{MHz}$, and $500 \mathrm{~W}$, respectively.

resolution of the RFEA and the spatially broadened potential drop near the thruster exit over about $10 \mathrm{~cm}$ scale as in Figure 8.

Both the ion beam energy and the electron temperature have been observed to increase with a decrease in the operating gas pressure (or the gas flow rate) $[22,23]$. This change in the ion beam energy can be interpreted as a result of the flux balance between the accelerated ions and the electrons overcoming the potential drop, as discussed in Ref. [20, 21, 45]. Figure 9 shows the measured plasma potential $V_{\mathrm{p}}$, the beam potential $V_{\text {beam }}$, the beam energy $\varepsilon_{\text {beam }}=V_{\text {beam }}-V_{\text {p }}$, and the electron temperature $T_{\mathrm{e}}$, as functions of the gas flow rate $C_{\mathrm{Ar}}$. The present results also show the similar trends to the previous observations [22, 23] and the detected beam energy is about 3-3.5 times as large as the electron temperature over the pressure range tested here. This 

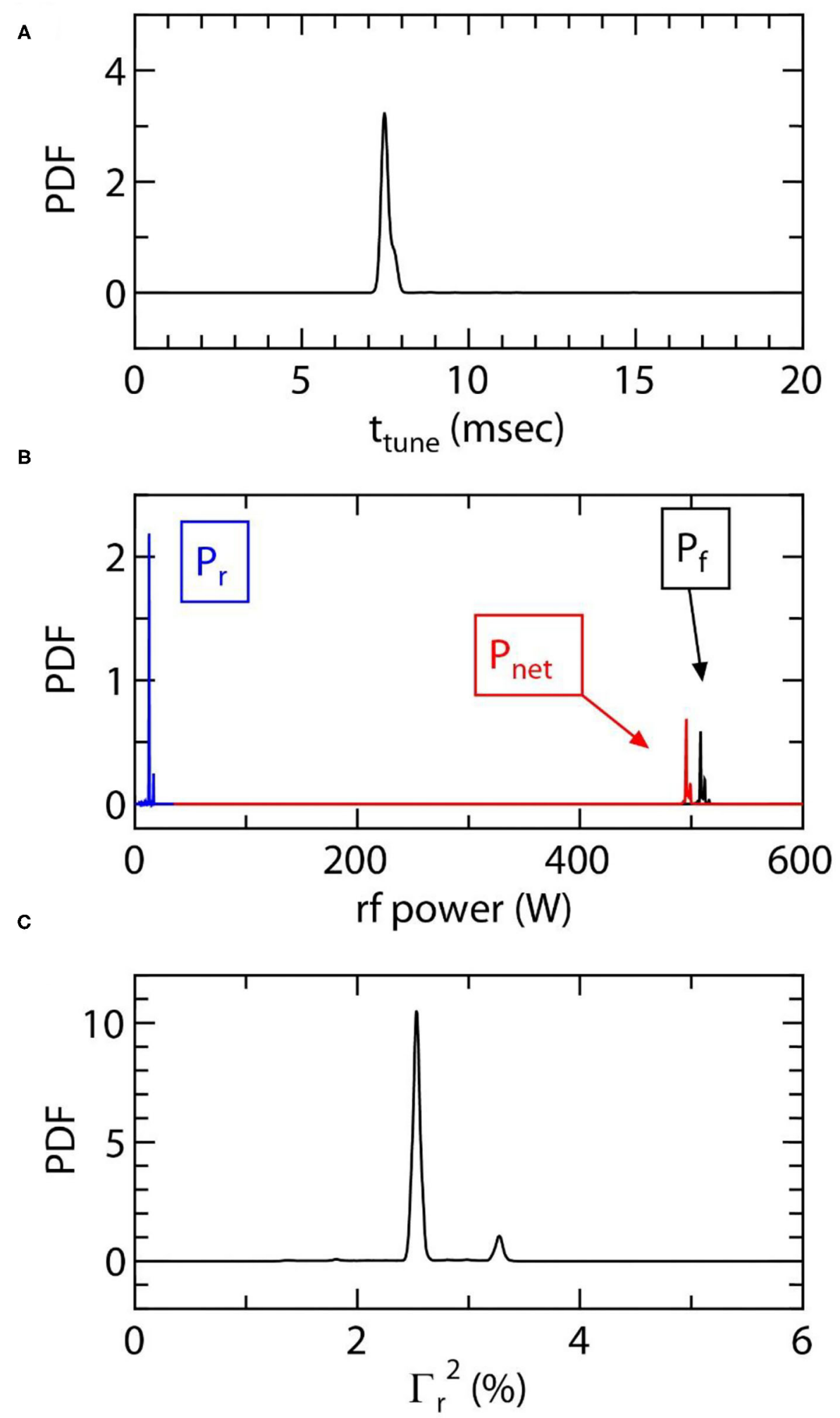

FIGURE 4 | Probability density functions (PDFs) of (A) the tuning time $t_{\text {tune }}$ (B) the forward power $P_{f}$ (a black solid line), the reflected power $P_{\mathrm{r}}$ (a blue solid line), the net power $P_{\text {net }}\left(\mathrm{a}\right.$ red solid line), and (C) the square of the reflection coefficient $\Gamma_{\mathrm{r}}^{2}$. These are obtained from the data taken by 1,000 shots repetition. 


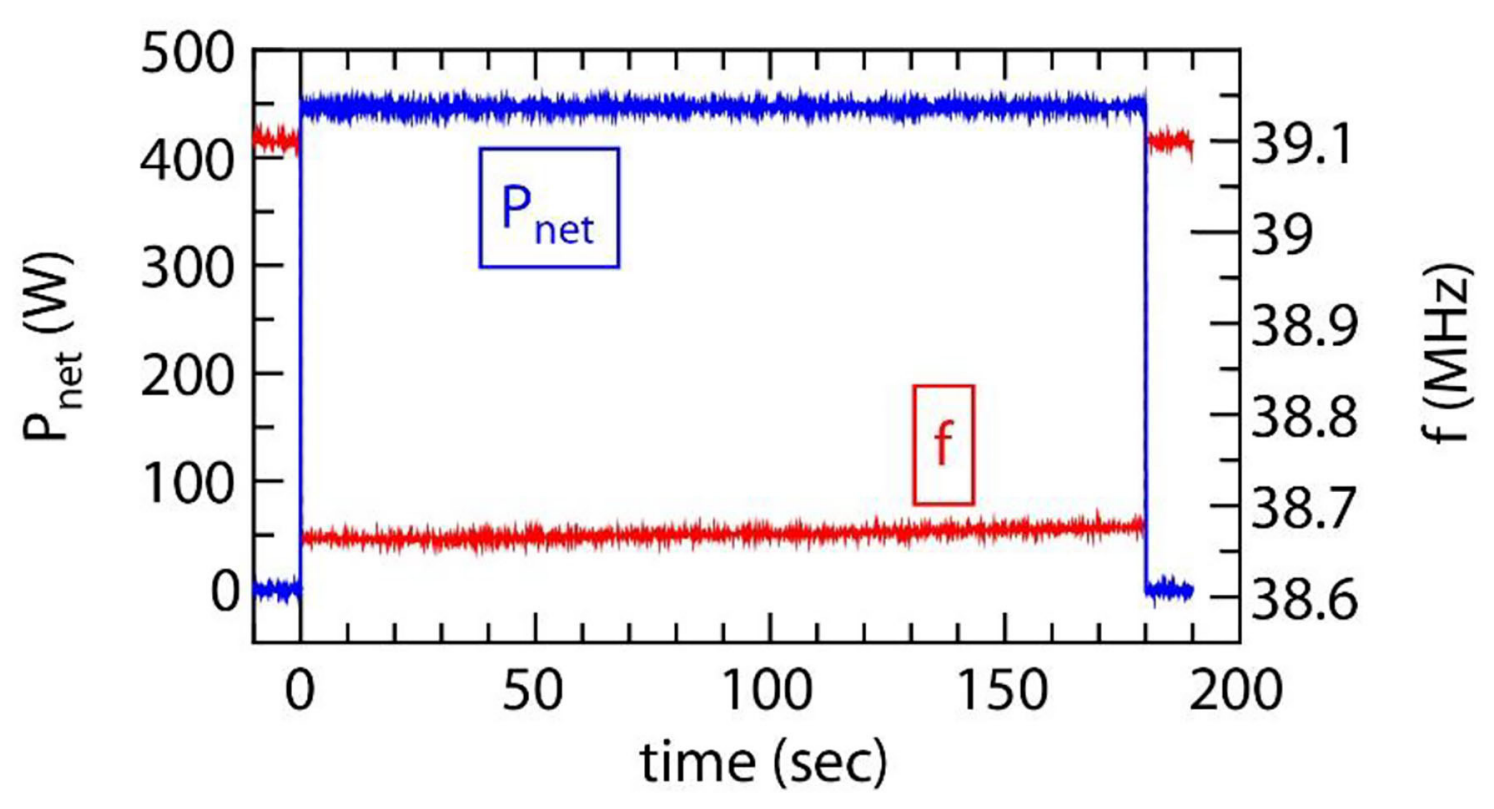

FIGURE 5 | Temporal evolutions of the net power $P_{\text {net }}$ (a blue solid line) and the if frequency $f$ (a red solid line), where the pulse width and the target value of the net power are set at $180 \mathrm{~s}$ and $450 \mathrm{~W}$, respectively.

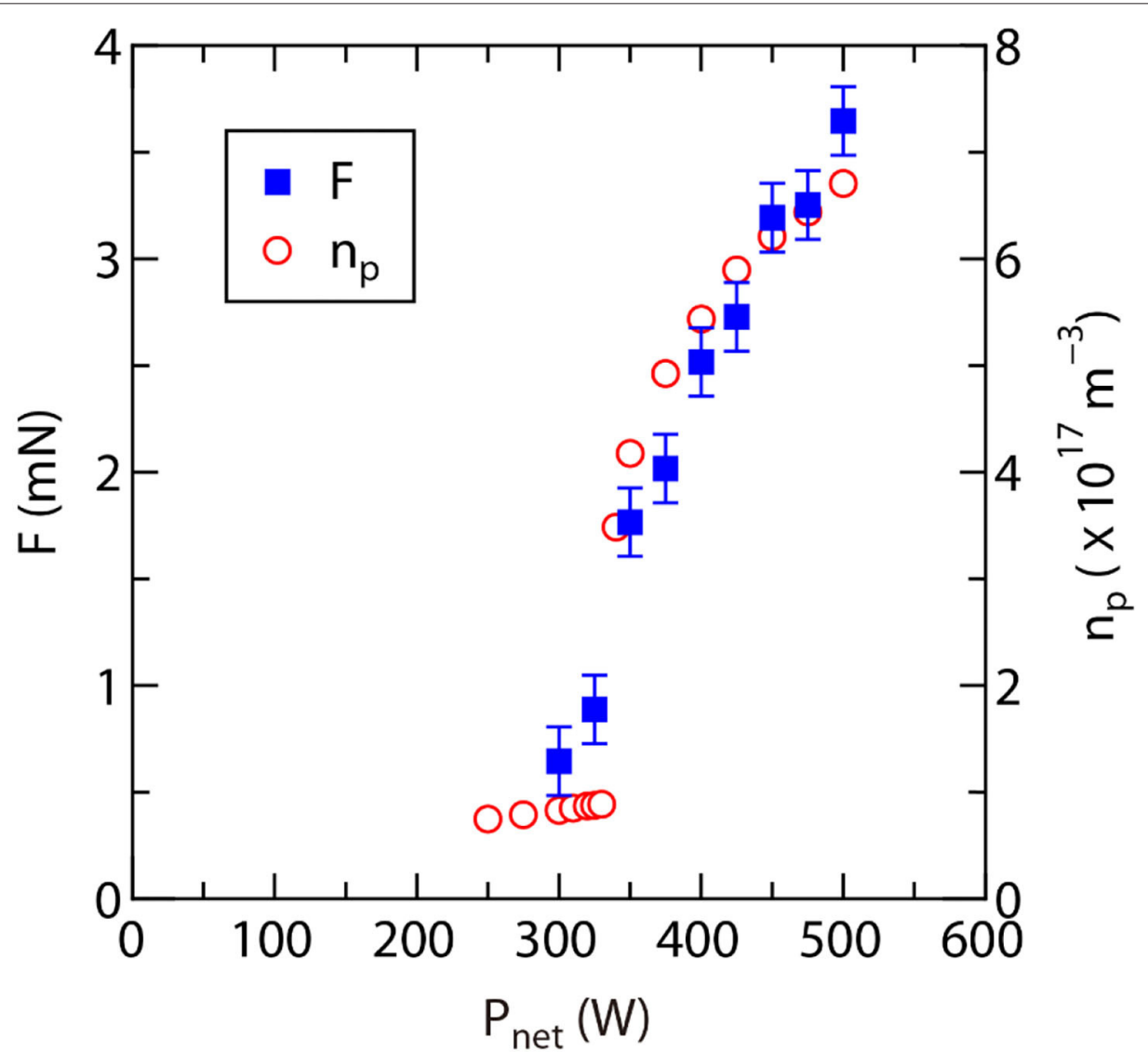

FIGURE 6 | Thrust $F$ measured by the thrust balance and plasma density $n_{\mathrm{p}}$ taken at $z=-10 \mathrm{~cm}$ as functions of the net power $P_{\text {net }}$. 

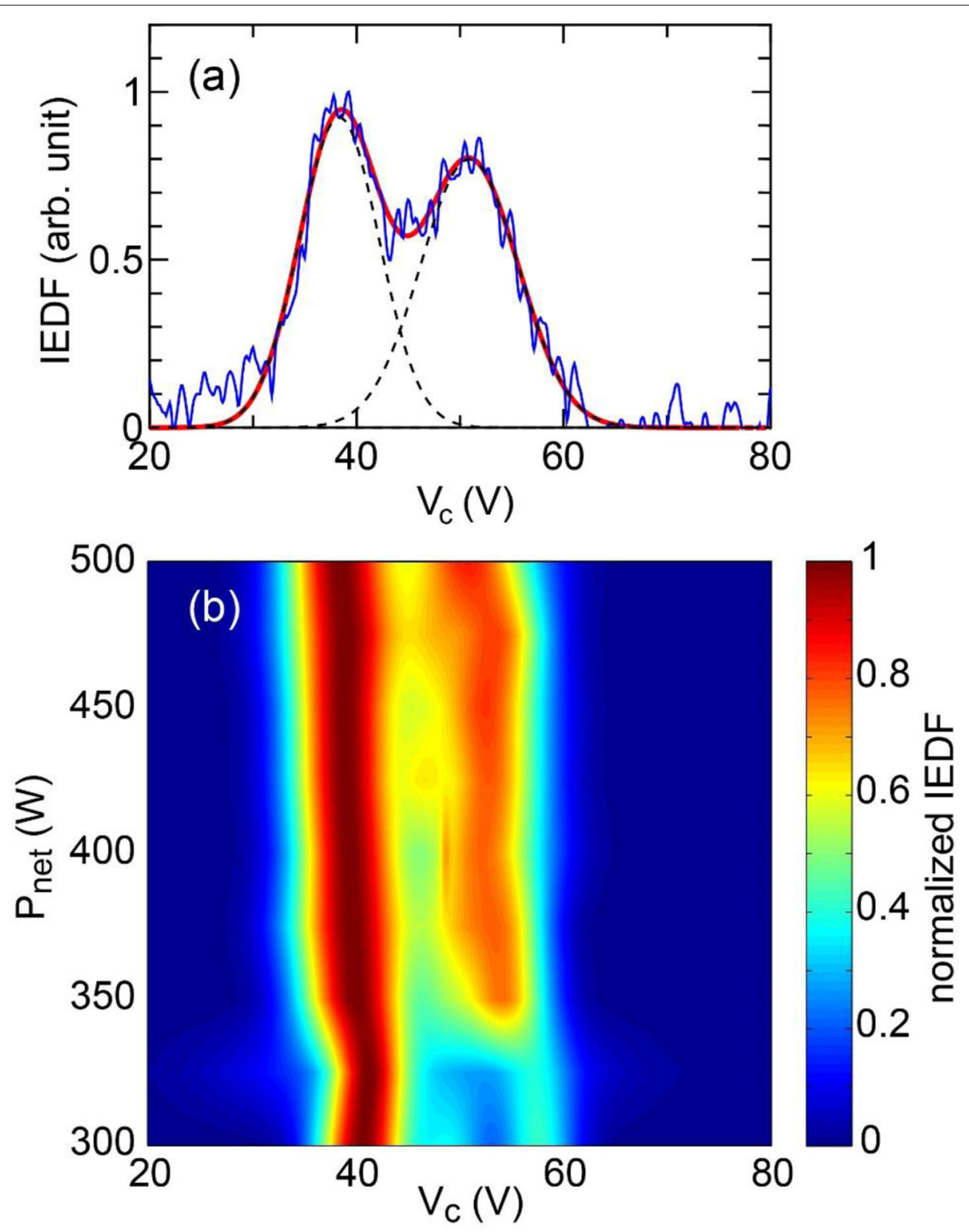

FIGURE 7 | (a) IEDF (a blue solid line) taken at $z=25 \mathrm{~cm}$ together with the Gaussian fitting curve (a red solid line) given by the sum of the two Gaussians drawn by dashed lines, where the gas flow rate and the net if power are chosen as $70 \mathrm{sccm}$ and $500 \mathrm{~W}$, respectively. (b) Contour plot of the normalized IEDF as a function of the net if power $P_{\text {net }}$, where the Gaussian fitting curves are used to draw the contour plot.

value is different from the potential drop estimation satisfying the flux balance between the ions and electrons for the Maxwellian electron energy distribution, i.e., $\sim 5.2 T_{\mathrm{e}}$. This discrepancy seems to be due to the assumption of the Maxwellian electron energy distribution, since the previously measured energy distribution has a depleted tail and close to the Druyvesteyn rather than the Maxwellian [23]. Therefore, the detailed measurement of the electron energy distribution is required to verify the flux balance between the electrons and ions. The characteristics of the ion beam and the imparted thrust similar to the previous experiments show that the fast- and automatically-controlled rf power system does not impact the thruster performance, while it would be important technique to operate the thruster for the undefined composition of the propellant, e.g., the air-breathing electric propulsion. When the imparted thrust is expected to be changed by the propellant composition even if the impedance matching is well-performed, the rf output power has to be controlled to maintain the constant thrust level, which remains further development issue.

Since the rf generator includes the similar components, such as the oscillator, the amplifier, and the power sensors, the weight and size of the rf generator would be similar to 


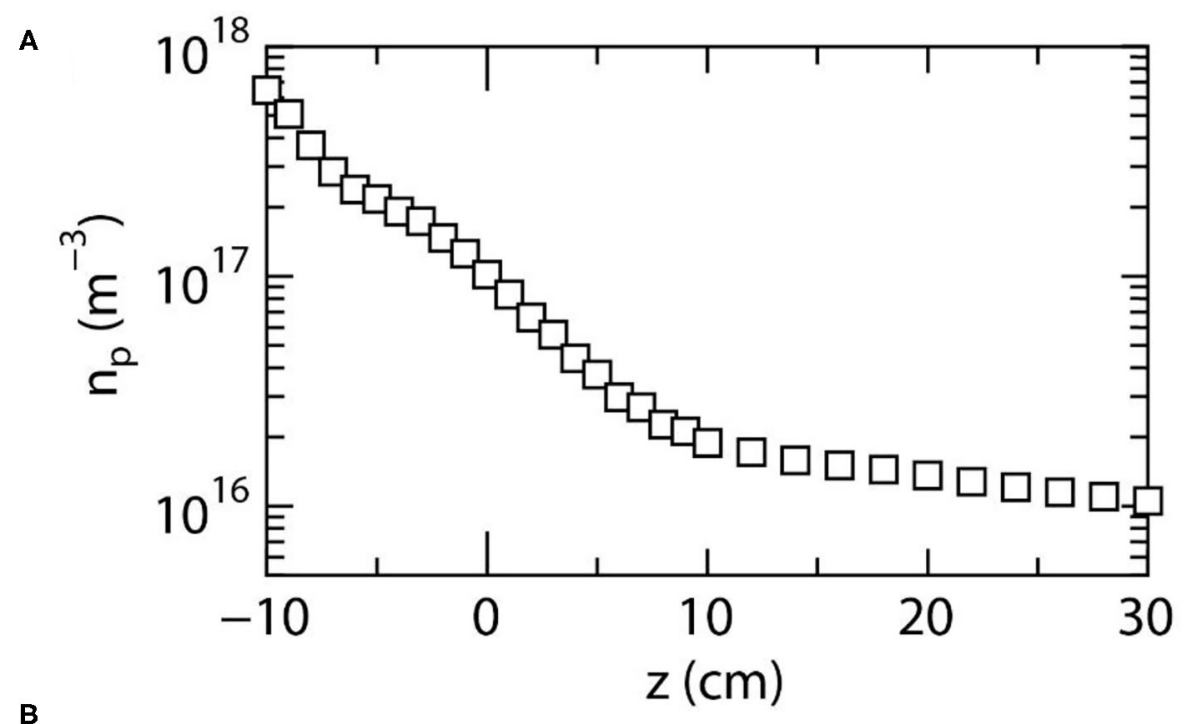

B

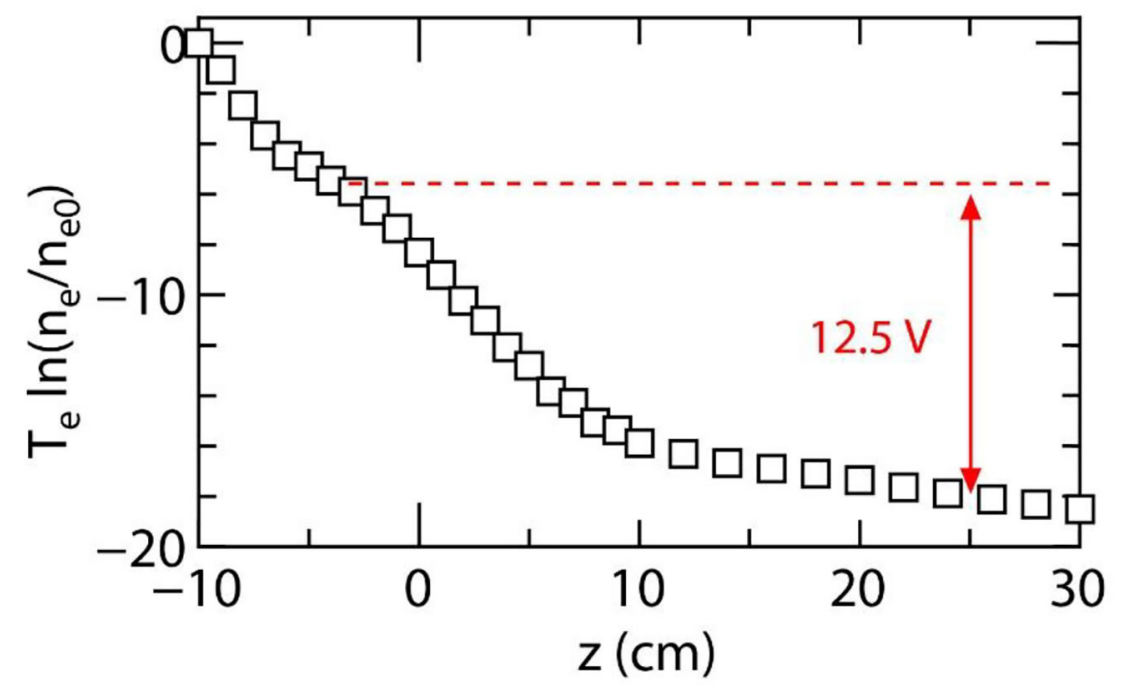

FIGURE 8 | (A) Axial profile of the measured plasma density $n_{\mathrm{p}}$ on the $z$ axis for $P_{\text {net }}=500 \mathrm{~W}$ and $C_{\mathrm{Ar}}=70 \mathrm{sccm}$. (B) Voltage $V$ from the reference position $(z=$ $-10 \mathrm{~cm}$ ) calculated from the Boltzmann relation assuming a uniform electron temperature, where the measured temperature of $T_{\mathrm{e}}=4.5 \mathrm{eV}$ is used for the calculation. The dashed line and the arrow indicate the potential difference corresponding to the beam energy of $\varepsilon_{\text {beam }} \sim 12.5 \mathrm{eV}$ [seen in Figure 7a], implying that the beam ions are accelerated from the source tube.

the traditional rf system. However, the use of only the fixed capacitors in the matching circuit would reduce the size and weight of the matching circuit, as the traditional system includes the large size variable capacitors and the mechanical motors. Typical weight and size of the commercial and traditional $\mathrm{rf}$ system for semiconductor process seem to be $5-10 \mathrm{~kg}$ and $10 \times 20 \times 30 \mathrm{~cm}^{3}$ for the matching circuit (including the variable capacitors and the mechanical controllers), and about $10 \mathrm{~kg}$ and $15 \times 45 \times 25 \mathrm{~cm}^{3}$ for the $\mathrm{rf}$ generator. It is expected that the matching circuit can be contained in about $5 \times 5 \times 5 \mathrm{~cm}^{3}$ in size and $<1 \mathrm{~kg}$ in weight for the frequency-tunable $\mathrm{rf}$ system. Therefore, the present system will roughly reduce the size and weight in half for the $500-\mathrm{W}$-class rf system.

\section{CONCLUSION}

The fast and automatically controlled frequency-tunable rf system is attached to the magnetic nozzle rf plasma thruster immersed in vacuum, where the $\mathrm{rf}$ frequency can be adjusted in the range of $37-43 \mathrm{MHz}$ and the maximum output power can be increased up to about $500 \mathrm{~W}$. The frequency and the output power are automatically controlled, yielding the minimized reflection coefficient and the net power maintained at a constant level with the good reproducibility and the stable steady-state operation. The maximum thrust of $3.5 \mathrm{mN}$ is obtained for the rf power of $\sim 500 \mathrm{~W}$, where the increase in the thrust can be observed simultaneously with the discharge mode transition. The presence of the supersonic ion beam is 

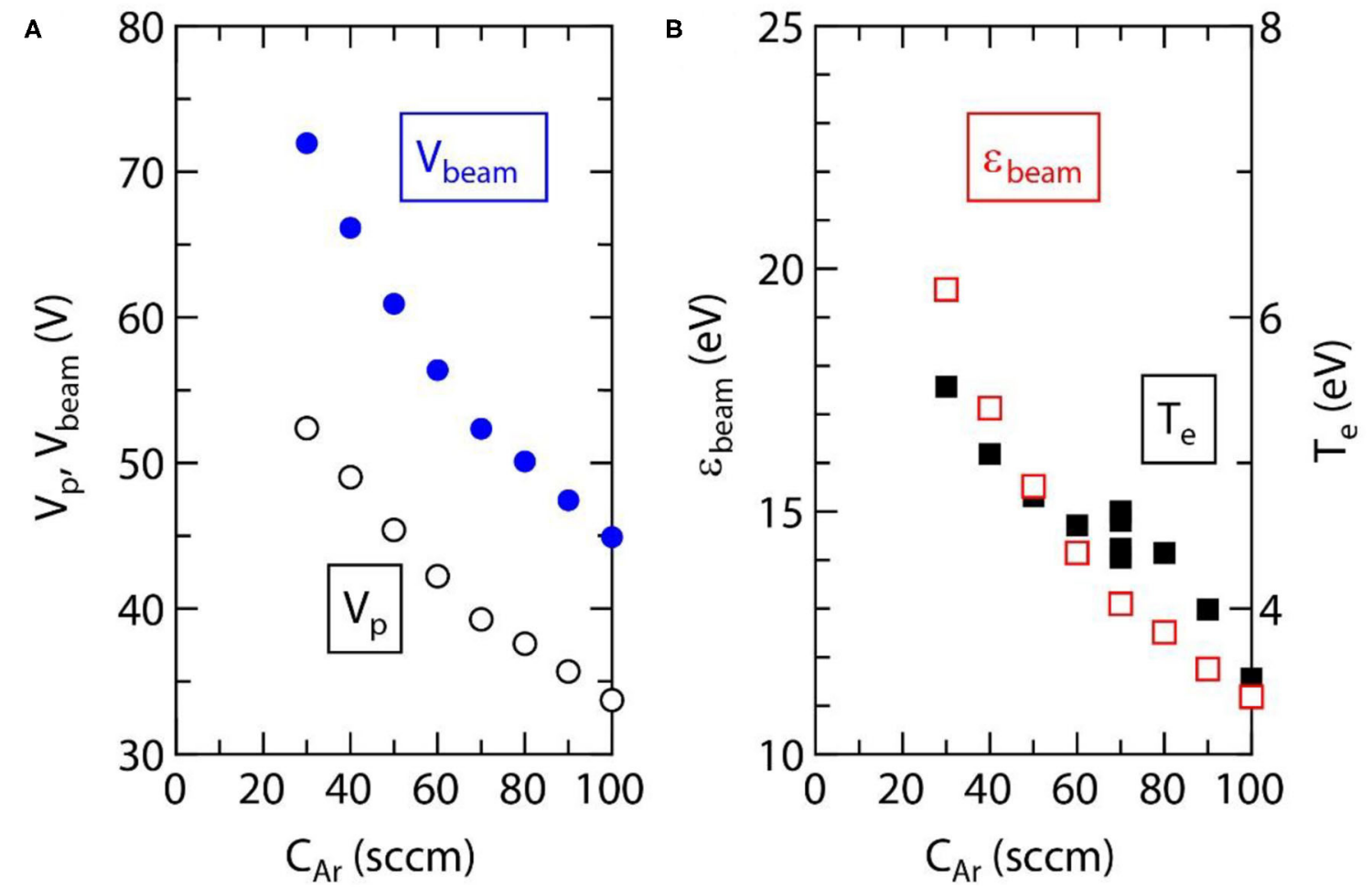

FIGURE 9 | (A) Plasma potential $V_{\mathrm{p}}$ (open circles) and beam potential $V_{\text {beam }}$ (filled circles) as functions of the gas flow rate $C_{\mathrm{Ar}}$, where these potentials are obtained from the Gaussian fitting curves (not shown here) of the measured IEDF at $z=25 \mathrm{~cm}$. (B) Calculated ion beam energy $\varepsilon_{\text {beam }}$ (open squares) from the data in (A) and electron temperature $T_{e}$ (filled squares) taken at $z=10 \mathrm{~cm}$ as functions of $C_{\mathrm{Ar}}$.

shown by the measurement of the ion energy distribution, where the enhancement of the ion beam component is detected simultaneously with the discharge mode transition. This implies that the high-density plasma production at the high-potential side is the key element of the ion beam generation. The present results show that the fast- and automatically-controlled rf system does not impact the thruster performance, being useful to reduce the size and the weight of the rf system.

\section{DATA AVAILABILITY STATEMENT}

The original contributions presented in the study are included in the article/Supplementary Material, further inquiries can be directed to the corresponding author.

\section{REFERENCES}

1. Meier DL, Koide S, Uchida Y. Magnetohydrodynamic production of relativistic jets. Science. (2001) 291:84. doi: 10.1126/science.291.5501.84

2. Charles C. A review of recent laboratory double layer experiments. Plasma Sources Sci Technol. (2007) 16:R1. doi: 10.1088/0963-0252/16/4/R01

3. Charles C, Boswell RW, Hawkins R. Oblique double layers: a comparison between terrestrial and auroral measurements. Phys Rev Lett. (2009) 103:095001. doi: 10.1103/PhysRevLett.103.095001

\section{AUTHOR CONTRIBUTIONS}

KT designed the concepts of the experiment, the setup, and the frequency-tunable rf system. The setup was performed by KT, RI, and $\mathrm{KH}$. The data were taken by all authors and analyzed by KT. The results were discussed by all authors. The manuscript written by $\mathrm{KT}$ was reviewed by $\mathrm{RI}$ and $\mathrm{KH}$.

\section{FUNDING}

This work is partially supported by a grant-in-aid for scientific research (18K18746 and 19H00663) from the Japan Society for the Promotion of Science, A-step program by Japan Science and Technology Agency, and Casio Science Promotion Foundation.

4. Takahashi K, Igarashi Y, Fujiwara T. Plane and hemispherical potential structures in magnetically expanding plasmas. Appl Phys Lett. (2010) 97:041501. doi: 10.1063/1.34 67857

5. Williams LT, Walker MLR. Plume structure and ion acceleration of a helicon plasma source. IEEE Trans Plasma Sci. (2015) 43:1694. doi: 10.1109/TPS.2015.2419211

6. Charles C, Boswell RW. Current-free double-layer formation in a high-density helicon discharge. Appl Phys Lett. (2003) 82:1356. doi: 10.1063/1.1557319 
7. Sun X, Keesee AM, Biloiu C, Scime EE, Meige A, Charles C, et al. Observation of ion-beam formation in a current-free double layer. Phys Rev Lett. (2005) 95:025004. doi: 10.1103/PhysRevLett.95.025004

8. Plihon N, Chabert P, Corr CS. Experimental investigation of double layers in expanding plasmas. Phys Plasmas. (2007) 14:013506. doi: 10.1063/1.2424429

9. Takahashi K, Oguni K, Yamada H, Fujiwara T. Ion acceleration in a solenoid-free plasma expanded by permanent magnets. Phys Plasmas. (2008) 15:084501. doi: 10.1063/1.2965497

10. Virko VF, Virko YV, Slobodyan VM, Shamrai KP. The effect of magnetic configuration on ion acceleration from a compact helicon source with permanent magnets. Plasma Sources Sci Technol. (2010) 19:015004. doi: 10.1088/0963-0252/19/1/015004

11. Fredriksen A, Mishra LN, Byhring HS. The effects of downstream magnetic field on current-free double layers and beam formation in the Njord helicon plasma device. Plasma Sources Sci Technol. (2010) 19:034009. doi: 10.1088/0963-0252/19/3/034009

12. Wiebold M, Sung Y-T, Scharer E. Experimental observation of ion beams in the Madison helicon experiment. Phys Plasmas. (2011) 18:063501. doi: 10.1063/1.3596537

13. Longmier BW, Bering III EA, Carter MD, Cassady LD, Chancery WJ, Chang Díaz FR, et al. Ambipolar ion acceleration in an expanding magnetic nozzle. Plasma Sources Sci Technol. (2011) 20:015007. doi: 10.1088/0963-0252/20/1/015007

14. Cannat F, Lafleur T, Jarrige J, Chabert P, Elias P-Q, Packan D. Optimization of a coaxial electron cyclotron resonance plasma thruster with an analytical model. Phys Plasmas. (2015) 22:053503. doi: 10.1063/1.4920966

15. Little J, Choueiri EY. Electron cooling in a magnetically expanding plasma. Phys Rev Lett. (2016) 117:225003. doi: 10.1103/PhysRevLett.117.225003

16. Zhang X, Aguirre E, Thompson DS, McKee J, Henriquez M, Scime EE. Pressure dependence of an ion beam accelerating structure in an expanding helicon plasma. Phys Plasmas. (2018) 25:023503. doi: 10.1063/1.5018583

17. Charles C, Boswell RW. The magnetic-field-induced transition from an expanding plasma to a double-layer containing expanding plasma. Appl Phys Lett. (2007) 91:201505. doi: 10.1063/1.2814877

18. Takahashi K, Shida Y, Fujiwara T. Magnetic-field-induced enhancement of ion beam energy in a magnetically expanding plasma using permanent magnets. Plasma Sources Sci Technol. (2010) 19:025004. doi: 10.1088/0963-0252/19/2/025004

19. Takahashi K, Charles C, Boswell RW, Fujiwara T. Double-layer ion acceleration triggered by ion magnetization in expanding radiofrequency plasma sources. Appl Phys Lett. (2010) 97:141503. doi: 10.1063/1.3499653

20. Takahashi K, Charles C, Boswell RW, Kaneko T, Hatakeyama R. Measurement of the energy distribution of trapped and free electrons in a current-free double layer. Phys Plasmas. (2007) 14:114503. doi: 10.1063/1.2803763

21. Chen FF. Physical mechanism of current-free double layers. Phys Plasmas. (2006) 13:034502. doi: 10.1063/1.2179393

22. Lieberman MA, Charles C. Theory for formation of a lowpressure, current-free double layer. Phys Rev Lett. (2006) 97:045003. doi: 10.1103/PhysRevLett.97.045003

23. Takahashi K, Charles C, Boswell RW, Fujiwara T. Electron energy distribution of a current-free double layer: druyvesteyn theory and experiments. Phys Rev Lett. (2011) 107:035002. doi: 10.1103/PhysRevLett.107.035002

24. Takahashi K, Lafleur T, Charles C, Alexander P, Boswell RW, Perren M, et al. Direct thrust measurement of a permanent magnet helicon double layer thruster. Appl Phys Lett. (2011) 98:141503. doi: 10.1063/1.3577608

25. Pottinger S, Lappas V, Charles C, Boswell R. Performance characterization of a helicon double layer thruster using direct thrust measurements. J Phys D Appl Phys. (2011) 44:235201. doi: 10.1088/0022-3727/44/23/235201

26. Shabshelowitz A, Gallimore AD. Performance and probe measurements of a radio-frequency plasma thruster. J Propul Power. (2013) 29:919. doi: 10.2514/1.B34720

27. Williams LT, Walker MLR. Thrust measurements of a radio frequency plasma source. J Propul Power. (2013) 29:520. doi: 10.2514/1.B34574

28. Takahashi K, Komuro A, Ando A. Effect of source diameter on helicon plasma thruster performance and its high power operation. Plasma Sources Sci Technol. (2015) 24:055004. doi: 10.1088/0963-0252/24/5/055004
29. Vialis T, Jarrige J, Aanesland A, Packan D. Direct thrust measurement of an electron cyclotron resonance plasma thruster. J Propul Power. (2018) 34:1323. doi: 10.2514/1.B37036

30. Fruchtman A. Electric field in a double layer and the imparted momentum. Phys Rev Lett. (2006) 96:065002. doi: 10.1103/PhysRevLett.96.065002

31. Gesto FN, Blackwell BD, Charles C, Boswell RW. Ion detachment in the helicon double-layer thruster exhaust beam. J Propul Power. (2006) 22:24. doi: 10.2514/1.13914

32. Cox W, Charles C, Boswell RW, Hawkins R. Spatial retarding field energy analyzer measurements downstream of a helicon double layer plasma. Appl Phys Lett. (2008) 93:071505. doi: 10.1063/1.2965866

33. Takahashi K, Fujiwara T. Observation of weakly and strongly diverging ion beams in a magnetically expanding plasma. Appl Phys Lett. (2009) 94:061502. doi: 10.1063/1.3080205

34. Terasaka K, Yoshimura S, Ogiwara K, Aramaki M, Tanaka MY. Experimental studies on ion acceleration and stream line detachment in a diverging magnetic field. Phys Plasmas. (2009) 17:072106. doi: 10.1063/1.3457139

35. Takahashi K, Itoh Y, Fujiwara T. Operation of a permanent-magnetsexpanding plasma source connected to a large-volume diffusion chamber. $J$ Phys D Appl Phys. (2011) 44:015204. doi: 10.1088/0022-3727/44/1/015204

36. Hooper EB. Plasma detachment from a magnetic nozzle. J Propul Power. (1993) 9:757. doi: 10.2514/3.23686

37. Arefiev AV, Breizman BN. Magnetohydrodynamic scenario of plasma detachment in a magnetic nozzle. Phys Plasmas. (2005) 12:043504. doi: 10.1063/1.1875632

38. Deline CA, Bengtson RD, Breizman BN, Tushentsov MR, Jones JE, Chavers DG, et al. Plasma detachment from a magnetic nozzle. Phys Plasmas. (2009) 16:033502. doi: 10.1063/1.3080206

39. Ahedo E, Merino M. On plasma detachment in propulsive magnetic nozzles. Phys Plasmas. (2011) 18:053504. doi: 10.1063/1.3589268

40. Takahashi K, Ando A. Laboratory observation of a plasma-flow-state transition from diverging to stretching a magnetic nozzle. Phys Rev Lett. (2017) 118:225002. doi: 10.1103/PhysRevLett.118.225002

41. Little JM, Choueiri EY. Electron demagnetization in a magnetically expanding plasma. Phys Rev Lett. (2019) 123:145001. doi: 10.1103/PhysRevLett.123.145001

42. Ahedo E, Merino M. Two-dimensional supersonic plasma acceleration in a magnetic nozzle. Phys Plasmas. (2010) 17:073501. doi: 10.1063/1.3442736

43. Takahashi K, Lafleur $T$, Charles C, Alexander P, Boswell RW. Electron diamagnetic effect on axial force in an expanding plasma: experiments and theory. Phys Rev Lett. (2011) 107:235001. doi: 10.1103/PhysRevLett.107.235001

44. Takahashi K, Charles C, Boswell RW. Approaching the theoretical limit of diamagnetic-induced momentum in a rapidly diverging magnetic nozzle. Phys Rev Lett. (2013) 110:195003. doi: 10.1103/PhysRevLett.110.195003

45. Takahashi K. Helicon-type radiofrequency plasma thrusters and magnetic plasma nozzles. Rev Mod Plasma Phys. (2019) 3:3. doi: 10.1007/s41614-019-0024-2

46. Takahashi K, Charles C, Boswell RW, Ando A. Demonstrating a new technology for space debris removal using a bi-directional plasma thruster. Sci Rep. (2018) 8:14417. doi: 10.1038/s41598-018-32697-4

47. Chen FF, Torreblanca H. Large-area helicon source with permanent magnets. Plasma Phys Control Fusion. (2006) 49:A81. doi: 10.1088/0741-3335/49/5A/S07

48. Schonherr T, Komurasaki K, Romano F, Massuti-Ballester B, Herdrich G, Analysis of atmosphere-breathing electric propulsion. IEEE Trans Plasma Sci. (2015) 43:287. doi: 10.1109/TPS.2014.2364053

49. Ishimatsu T, Weck OL, Hoffman JA, Ohkami Y, Shishko R, Generalized multicommodity network flow model for the Earth-Moon-Mars logistics system. J. Spacecr Rockets. (2016) 53:25. doi: 10.2514/1.A33235

50. Ziemba T, Euripides P, Slough J, Winglee R, Giersch L, Carscadden J, et al. Plasma characteristics of a high power helicon discharge. Plasma Sources Sci Technol. (2006) 15:517. doi: 10.1088/0963-0252/15/3/030

51. Charles C, Boswell RW, Bish A. Variable frequency matching to a radiofrequency source immersed in vacuum. J Phys D Appl Phys. (2013) 46:365203. doi: 10.1088/0022-3727/46/36/365203 
52. Takahashi K, Nakano Y, Ando A. Frequency-tuning radiofrequency plasma source operated in inductively-coupled mode under a low magnetic field. $J$ Phys D Appl Phys. (2017) 50:265201. doi: 10.1088/1361-6463/aa7524

53. Charles C, Liang W, Raymond L, Rivas-Davila J, Boswell RW. Vacuum testing a miniaturized switch mode amplifier powering an electrothermal plasma micro-thruster. Front Phys. (2017) 5:36. doi: 10.3389/fphy.2017.00036

54. Takahashi K, Hanaoka K, Ando A. Fast and automatic control of a frequency-tuned radiofrequency plasma source. Front Phys. (2020) 7:227. doi: 10.3389/fphy.2019.00227

55. Takahashi K, Takao Y, Ando A. Thrust imparted by a steppeddiameter magnetic nozzle rf plasma thruster. Appl Phys Lett. (2018) 113:034101. doi: 10.1063/1.5041034

56. Takahashi K. Radiofrequency antenna for suppression of parasitic discharges in a helicon plasma thruster experiment. Rev Sci. Instrum. (2012) 83:083508. doi: 10.1063/1.4748271

57. Takahashi K, Takao Y, And A. Low-magnetic-field enhancement of thrust imparted by a stepped-diameter and downstream-gasinjected rf plasma thruster. Plasma Sources Sci Technol. (2019) 28:085014. doi: 10.1088/1361-6595/ab3100

58. Takahashi K, Komuro A, Ando A. Measurement of plasma momentum exerted on target by a small helicon plasma thruster and comparison with direct thrust measurement. Rev Sci Instrum. (2015) 86:023505. doi: 10.1063/1.4907797
59. Takahashi K, Charles C, Boswell R, Lieberman MA, Hatakeyama R. Characterization of the temperature of free electrons diffusing from a magnetically expanding current-free double layer plasma. $J$ Phys D Appl Phys. (2010) 43:162001. doi: 10.1088/0022-3727/43/16/ 162001

60. Hanaoka K, Takahashi K, Ando A. Reproducibility of a plasma production in a fast- and automatically-controlled radio frequency plasma source. IEEE Trans Plasma Sci. (2020) 48:2138. doi: 10.1109/TPS.2020.2987554

61. Charles C, Boswell RW. Laboratory evidence of a supersonic ion beam generated by a current-free "helicon" double layer. Phys Plasmas. (2004) 11:1706. doi: $10.1063 / 1.1652058$

Conflict of Interest: The authors declare that the research was conducted in the absence of any commercial or financial relationships that could be construed as a potential conflict of interest.

Copyright (c) 2021 Takahashi, Imai and Hanaoka. This is an open-access article distributed under the terms of the Creative Commons Attribution License (CC BY). The use, distribution or reproduction in other forums is permitted, provided the original author(s) and the copyright owner(s) are credited and that the original publication in this journal is cited, in accordance with accepted academic practice. No use, distribution or reproduction is permitted which does not comply with these terms. 